Supporting Information

\title{
Thermoelectric and mechanical properties of
}

\section{environmentally friendly $\mathrm{Mg}_{2} \mathrm{Si}_{0.3} \mathrm{Sn}_{0.67} \mathrm{Bi}_{0.03} / \mathrm{SiC}$}

\section{composites}

Leilane R. Macario ${ }^{\dagger}$, Yixuan Shi ${ }^{\dagger}$, Parisa Jafarzadeh ${ }^{\dagger}$, Tianze Zou ${ }^{\dagger+}$, Jan B. Kycia ${ }^{\dagger \dagger}$, Holger Kleinke*,

${ }^{\dagger}$ Department of Chemistry and Waterloo Institute for Nanotechnology, University of Waterloo, Waterloo, ON N2L 3G1, Canada

${ }^{\dagger+}$ Department of Physics and Astronomy and Guelph-Waterloo Physics Institute, University of Waterloo, Waterloo, ON, Canada N2L 3G1

*Email: kleinke@uwaterloo.ca 
Table S1. Area scan results (percentages) of the $\mathrm{Mg}_{2} \mathrm{Si}_{0.30} \mathrm{Sn}_{0.67} \mathrm{Bi}_{0.03}$ sample.

\begin{tabular}{ccccc}
\hline Area & $\mathrm{Mg}$ & $\mathrm{Si}$ & $\mathrm{Sn}$ & $\mathrm{Bi}$ \\
\hline 1 & 66.1 & 10.5 & 22.4 & 1.0 \\
2 & 66.6 & 10.3 & 22.2 & 0.9 \\
3 & 66.4 & 10.1 & 22.8 & 0.7 \\
Average & 66.3 & 10.3 & 22.5 & 0.9 \\
Nominal composition wt.-\% & 66.7 & 10.0 & 22.3 & 1.0 \\
\hline
\end{tabular}

Table S2. Densities and specific heat of $\mathrm{Mg}_{2} \mathrm{Si}_{0.30} \mathrm{Sn}_{0.67} \mathrm{Bi}_{0.03} / \mathrm{SiC}$ composites.

\begin{tabular}{|c|c|c|c|}
\hline Sample & $\begin{array}{c}\text { Density Archimedes } \\
\left(\mathrm{g} . \mathrm{cm}^{-1}\right)\end{array}$ & $\begin{array}{l}\text { Theoretical density } \\
(\%)\end{array}$ & $\mathrm{Cp}$ \\
\hline $\mathrm{Mg}_{2} \mathrm{Si} 0.30 \mathrm{Sn} 0.67 \mathrm{Bi} 0.03$ & 3.19 & 99 & 0.524 \\
\hline $\mathrm{Mg}_{2} \mathrm{Si}_{0.30} \mathrm{Sn}_{0.67} \mathrm{Bi}_{0.03}+0.5$ wt- $\% \mathrm{SiC}$ & 3.18 & 98 & 0.527 \\
\hline $\mathrm{Mg}_{2} \mathrm{Si}_{0.30} \mathrm{Sn}_{0.67} \mathrm{Bi}_{0.03}+1.0$ wt- $\% \mathrm{SiC}$ & 3.19 & 99 & 0.531 \\
\hline $\mathrm{Mg}_{2} \mathrm{Si}_{0.30} \mathrm{Sn}_{0.67} \mathrm{Bi}_{0.03}+1.5$ wt- $\% \mathrm{SiC}$ & 3.18 & 98 & 0.535 \\
\hline $\mathrm{Mg}_{2} \mathrm{Si}_{0.30} \mathrm{Sn}_{0.67} \mathrm{Bi}_{0.03}+3.0 \mathrm{wt}-\% \mathrm{SiC}$ & 3.18 & 98 & 0.545 \\
\hline
\end{tabular}

Equation S1. Hashin model ${ }^{1}$.

$$
E_{c}=E_{m}\left(\frac{E_{m} V_{m}+E_{r}\left\{V_{r}+1\right\}}{E_{r} V_{m}+E_{m}\left\{V_{r}+1\right\}}\right),
$$

where, $E_{\mathrm{c}}$ is Young's modulus of the composite, $E_{\mathrm{m}}$ is Young's modulus of the matrix, $E_{\mathrm{r}}$ is Young's modulus of the reinforcing phase $\left(E_{\mathrm{r}} \text { equals to } 440 \mathrm{GPa}\right)^{2}, V_{\mathrm{m}}$ is volume fraction of the matrix, and $V_{\mathrm{r}}$ is volume fraction of the reinforcing phase (here: $\mathrm{SiC}$ ). 


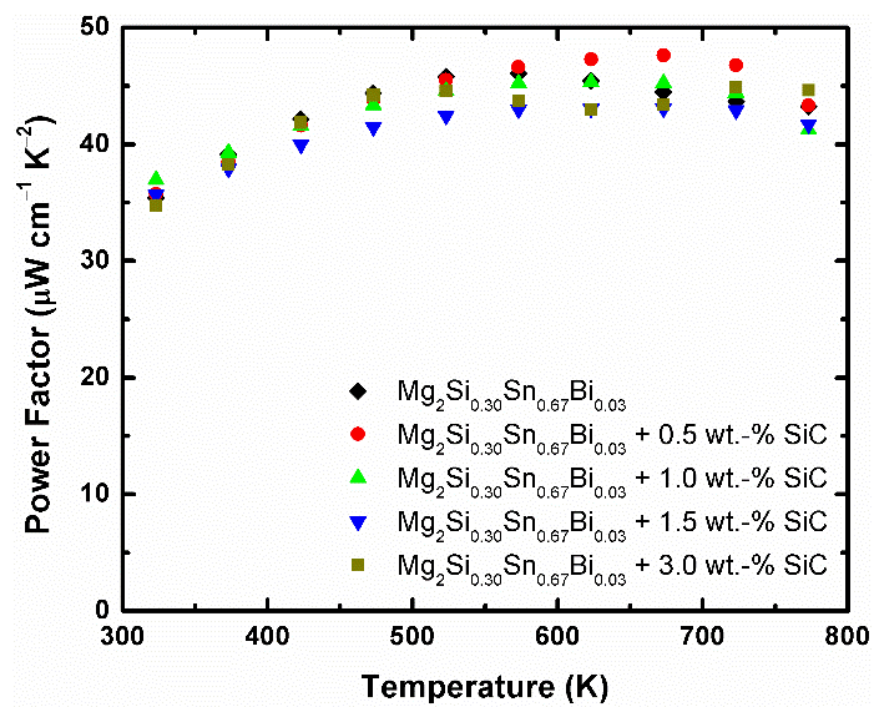

Figure S1. Power factor of $\mathrm{Mg}_{2} \mathrm{Si}_{0.30} \mathrm{Sn}_{0.67} \mathrm{Bi} 0.03$ composites with $0,0.5,1.0,1.5$, and 3.0 wt.-\% of $\mathrm{SiC}$.

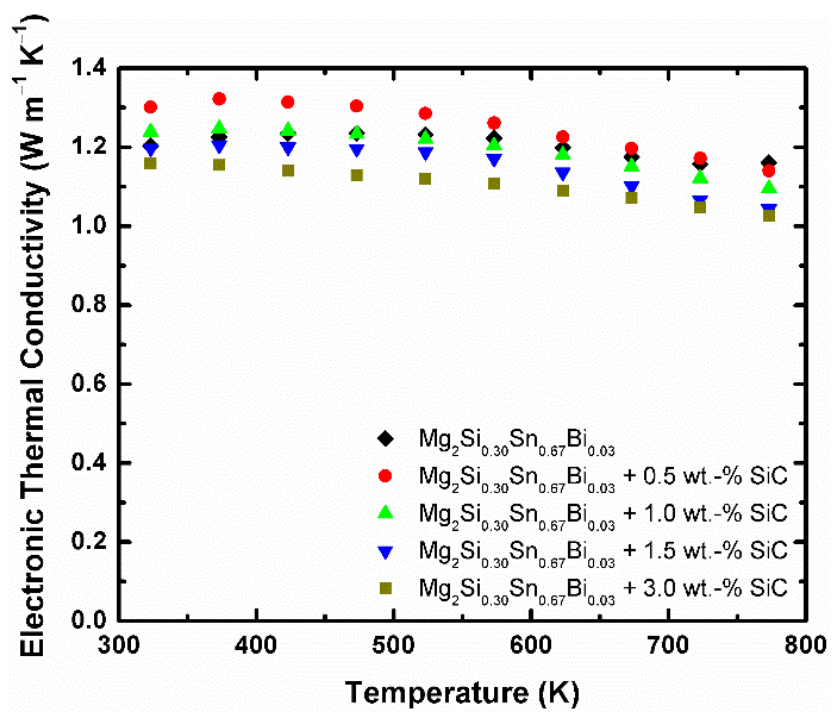

Figure S2. Calculated electronic thermal conductivity of $\mathrm{Mg}_{2} \mathrm{Si}_{0.30} \mathrm{Sn}_{0.67} \mathrm{Bi}_{0.03}$ composites with 0 , $0.5,1.0,1.5$, and $3.0 \mathrm{wt.} . \%$ of $\mathrm{SiC}$. 


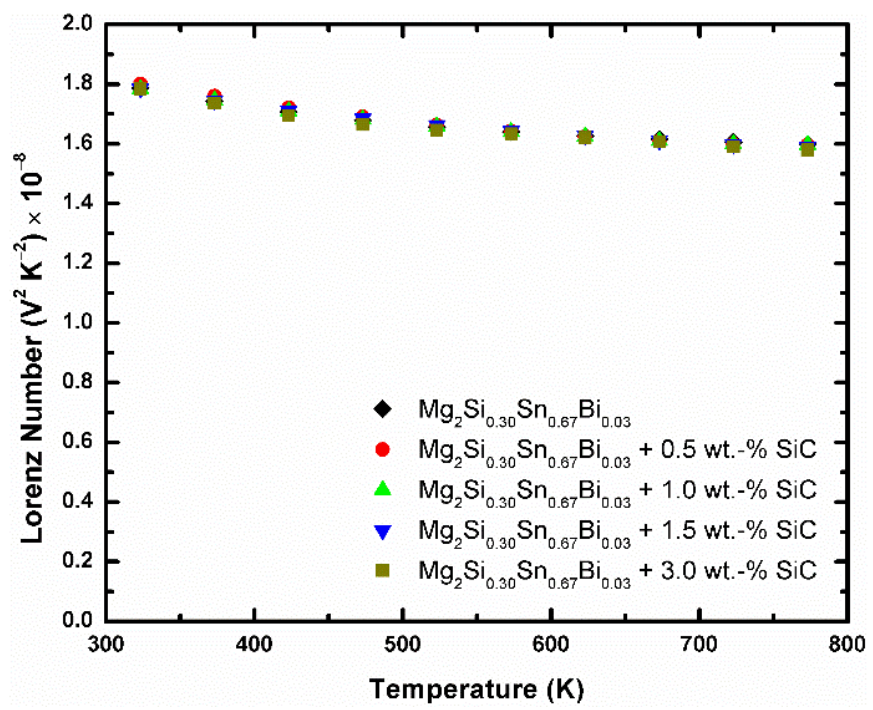

Figure S3. Calculated Lorenz numbers between $300 \mathrm{~K}$ and $800 \mathrm{~K}$ of $\mathrm{Mg}_{2} \mathrm{Si} \mathrm{i}_{0.30 \mathrm{Sn}} .67 \mathrm{Bi} 0.03$ composites with $0,0.5,1.0,1.5$, and $3.0 \mathrm{wt} .-\%$ of $\mathrm{SiC}$.

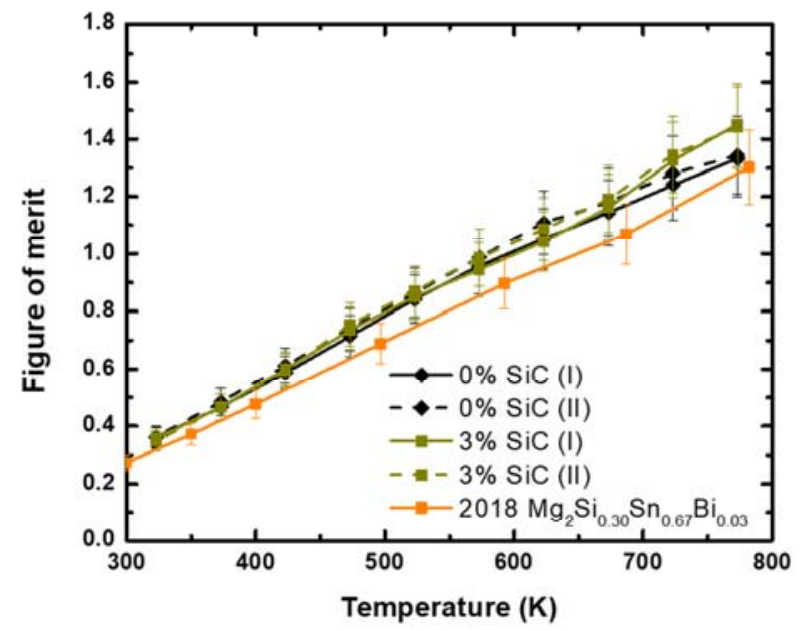

Figure S4. Figure of merit values from the two different pellets of $\mathrm{Mg}_{2} \mathrm{Si}_{0.30} \mathrm{Sn}_{0.67} \mathrm{Bi} 0.03$ (black symbols); $\mathrm{Mg}_{2} \mathrm{Si}_{0.30} \mathrm{Sn}_{0.67} \mathrm{Bi}_{0.03} / 3.0$ wt.- $\% \mathrm{SiC}$ composite (mustard symbols), compared to the 2018 data on $\mathrm{Mg}_{2} \mathrm{Si}_{0.30} \mathrm{Sn}_{0.67} \mathrm{Bi}_{0.03}$ (orange symbol). 

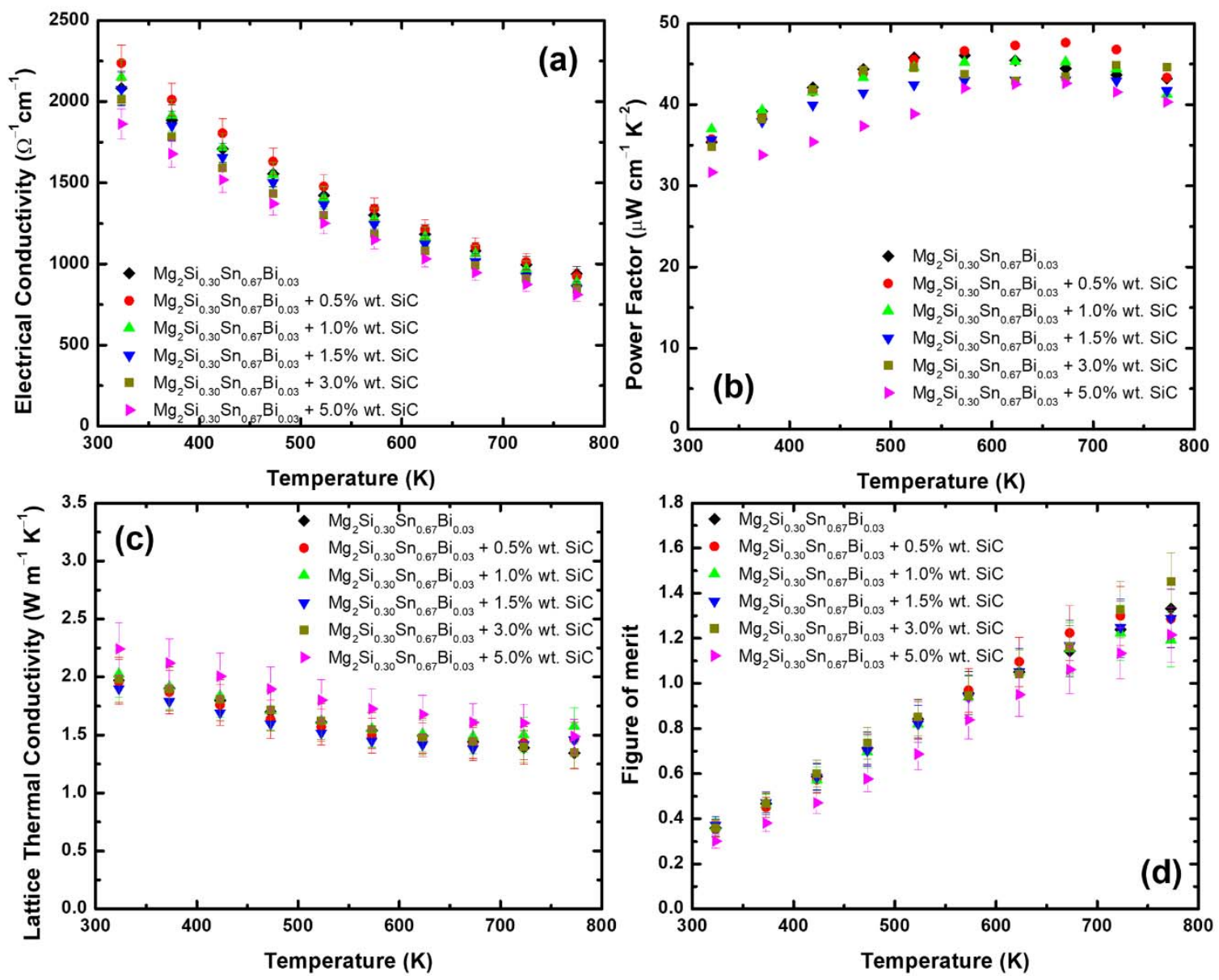

Figure S5. Electrical conductivity, power factor, lattice thermal diffusivity, and figure of merit of $\mathrm{Mg}_{2} \mathrm{Si}_{0.30} \mathrm{Sn}_{0.67} \mathrm{Bi}_{0.03}$ composites with $0,0.5,1.0,1.5,3.0$, and 5.0 wt.-\% of $\mathrm{SiC}$. 


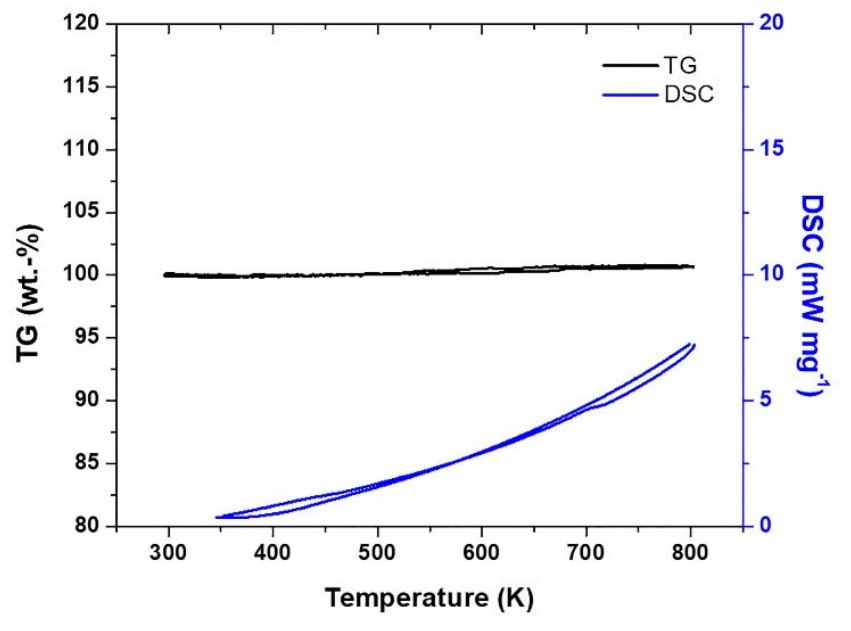

Figure S6. TG and DSC of $\mathrm{Mg}_{2} \mathrm{Si}_{0.3} \mathrm{Sn}_{0.67} \mathrm{Bi} 0.03$.

\section{REFERENCES}

(1) Hashin, Z. The Elastic Moduli of Heterogeneous Materials. J. Appl. Mech. 1962, 29 (1), 143-150.

(2) Schreiber, E.; Soga, N. Elastic Constants of Silicon Carbide. J. Am. Ceram. Soc. 1966, 49 (6), 342-342. 